COMUNICACIÓN CIENTÍfICA IX CONGRESO NACIONAL DE LA SOCIEDAD CIENTÍFICA ESPAÑOLA DE ENFERMERÍA - SCELE. Mayo de 2018. UNIVERSIDAD DE ALICANTE.

\title{
HÉROES INVISIBLES SIN CAPA: EL SENTIMIENTO DE VULNERABILIDAD EN ENFERMERÍA DURANTE EL ATENTADO DE LAS RAMBLAS, BARCELONA
}

MC. Olivé Ferrer
A. Martínez Rodríguez
G. Sánchez Rueda
C. Valiente Ballesteros
L. Tejero Vidal
O. Bautista Villaécija

Facultad Medicina i Ciències salud, Escola Infermeria U. de Barcelona. 


\section{PALABRAS CLAVE:}

Enfermería, vulnerabilidad, atentado terrorista, experiencia vital.

\section{Introducción}

Se presentan resultados preliminares, de un estudio más amplio, en relación con la percepción de vulnerabilidad de profesionales de enfermería, durante la atención a las víctimas en el atentado de las Ramblas de Barcelona de agosto 2017.

Según la OMS se considera catástrofe media cuando hay una afectación de entre 100 y 1000 víctimas. En un incidente con múltiples lesionados (iMuLe) debe garantizarse la atención adecuada y la seguridad de los intervinientes.

\section{Objetivo}

Mostrar, mediante narrativa, la vivencia o no de vulnerabilidad y seguridad en la atención a las víctimas en el atentado de Barcelona.

\section{Métodos}

Estudio que se enmarca en el paradigma cualitativo y de metodología fenomenológica. El muestreo es intencionado. Los participantes son profesionales de enfermería que atendieron a afectados en el atentado de Barcelona de 2017 en diferentes contextos. La generación de información se ha hecho mediante entrevistas en profundidad, relatos escritos y documentación. Se ha hecho un análisis interpretativo, atendiendo a la categoría de vivencia de seguridad/ vulnerabilidad y se presenta como narrativa.

\section{Resultados y análisis}

Inés es madre primeriza y enfermera experta. Ginés no llega a la treintena y llevaba un mes en el SEM el día del atentado. Los dos tienen claras sus funciones enfermeras desde una perspectiva humanista y en contextos de emergencias. Los dos vivieron la atención a las víctimas del atentado. La vulnerabilidad la percibieron de forma distinta, Inés pensaba en su integridad física mientras atendía ¿podía repetirse la acción terrorista? ¿Pueden ser los baños un buen escondite? Quizás muchas películas, o quizás la nueva maternidad le da un motivo más para la protección. Quería estar en dos sitios a la vez, en su casa y allí, haciendo su trabajo, pero la percepción de riesgo y vulnerabilidad la vivió hasta llegar a su casa, más allá de la medianoche y abrazar a su hija; sigue percibiendo la inseguridad y piensa que la experiencia, la formación y el tiempo contribuyen a gestionar sus sentimientos.

Ginés no ha vuelto a pisar las Ramblas, percibió cierta tranquilidad después de avisar a su familia para que no se acercaran al lugar del atentado. Ahora recuerda que trabajó cerca de la furgoneta sin pensar que podía haber explosivos y mientras corría la información que había un tirador. Cogió aire y se concentró en hacer el máximo por las víctimas. Trabajó en la calle con mucha energía, actuó según su experiencia en los accidentes y siguiendo las indicaciones de la central. Acabado el servicio les ofrecieron atención psicológica, pero su deseo era acercarse a los suyos, sentir su calor, llorar, ver la televisión y captar la magnitud de lo sucedido y vivido. Me quedé tranquilo, nos dice, he hecho lo que había que hacer, no soy un héroe, soy un enfermero entusiasta de mi trabajo.

\section{Discusión}

Aunque la búsqueda de seguridad es la primera recomendación en las situaciones de iMuLe, la complejidad del momento y la desinformación, modularon la percepción de seguridad, aunque su falta, no fueron un impedimento para una atención adecuada. 